\title{
On the effect of x-ray irradiation on the deformation and fracture behavior of human cortical bone
}

\author{
Holly D. Barth ${ }^{a, b, c, t}$, Maximilien E. Launey ${ }^{a, t}$, Alastair A. MacDowell ${ }^{b}$ \\ Joel W. Ager III ${ }^{a}$ and Robert O. Ritchie ${ }^{a, c, *}$ \\ aMaterials Sciences Division, Lawrence Berkeley National Laboratory, Berkeley, CA 94720, USA \\ 'Experimental Systems Group, Lawrence Berkeley National Laboratory, Berkeley, CA 94720, USA \\ 'Department of Materials Science \& Engineering, University of California, Berkeley, CA 94720, USA
}

\begin{abstract}
In situ mechanical testing coupled with imaging using high-energy synchrotron x-ray diffraction or tomography imaging is gaining in popularity as a technique to investigate micrometer and even sub-micrometer deformation and fracture mechanisms in mineralized tissues, such as bone and teeth. However, the role of the irradiation in affecting the nature and properties of the tissue is not always taken into account. Accordingly, we examine here the effect of x-ray synchrotron-source irradiation on the mechanistic aspects of deformation and fracture in human cortical bone. Specifically, the strength, ductility and fracture resistance (both work-of-fracture and resistancecurve fracture toughness) of human femoral bone in the transverse (breaking) orientation were evaluated following exposures to 0.05, 70, 210 and $630 \mathrm{kGy}$ irradiation. Our results show that the radiation typically used in tomography imaging can have a major and deleterious impact on the strength, post-yield behavior and fracture toughness of cortical bone, with the severity of the effect progressively increasing with higher doses of radiation. Plasticity was essentially suppressed after as little as $70 \mathrm{kGy}$ of radiation; the fracture toughness was decreased by a factor of five after $210 \mathrm{kGy}$ of radiation. Mechanistically, the irradiation was found to alter the salient toughening mechanisms, manifest by the progressive elimination of the bone's capacity for plastic deformation which restricts the intrinsic toughening from the formation "plastic zones" around crack-like defects. Deep-ultraviolet Raman spectroscopy indicated that this behavior could be related to degradation in the collagen integrity.
\end{abstract}

Keywords: Human cortical bone, x-ray radiation, deformation, toughness, collagen

\footnotetext{
${ }^{\dagger}$ Both authors contributed equally to this work

*Corresponding author. tel: +1-510-486-5798; fax: +1-510-643-5792. E-mail address: RORitchie@lbl.gov (R.O. Ritchie)
} 


\section{INTRODUCTION}

Human bone and tissue can be exposed to a wide range of radiation levels for medical and scientific reasons. At the low dose end, the average radiation from an abdominal x-ray is $\sim 1.4 \mathrm{mGy}$; that from a pelvic CT scan is $25 \mathrm{mGy}$ [1]. At the high dose end (>10 kGy), gamma irradiation is commonly used to terminally sterilize allograft tissues and bones [2-5], and has been proven to be very potent sterilization agent with the ability to effectively penetrate tissue. However, gamma irradiation is also known to adversely affect the mechanical and biological properties of tissue in a dose-dependent manner by degrading the collagen [6-14]. Specifically, gamma rays split polypeptide chains; in wet specimens, irradiation causes release of free radicals via radiolysis of water molecules that induces cross-linking reactions in collagen molecules [15-17].

International consensus on an optimum dose of radiation has not been reached due to wide range of confounding variables and individual decisions by tissue banks. This has resulted in the application of sterilization doses ranging from 25 to $35 \mathrm{kGy}$ [16], although even at such a "standard dose" the effect of irradiation on the mechanical integrity of bone and tissue is still controversial. For doses up to $35 \mathrm{kGy}$, several studies $[7,8,10,18-20]$ have reported a significant effect on the post-yield properties of cortical bone, in particular significant reductions in plastic properties such as ultimate strength and work-of-fracture, but little effect on the elastic properties, i.e., stiffness and elastic limit. Conversely, other studies on bones and tendons $[9,14,21,22]$ have claimed no significant reduction in biomechanical properties after similar doses. Nevertheless, a general consensus is that bones and tissues can be partially protected from free radical damage by treatment radioprotectants, i.e., deep freezing during radiation [19], or freeze drying and/or use of antioxicant ascorbate [23]. However, even though the impact of lower doses (e.g., 15 to $35 \mathrm{kGy}$ ) remains debatable, most studies agree that 
higher doses of gamma radiation (e.g., 40-60 kGy or more), which are expected to eliminate viral infection, can definitely lead to deleterious effects $[8,10]$.

The effect of irradiation is also a concern with scientific studies of the properties of bone and tissue using computed micro-tomography ( $\mu \mathrm{XCT})$ with synchrotron and desktop x-ray sources [24]. Surprisingly, this issue is often ignored but has become of importance as in situ testing with high-energy synchrotron x-ray diffraction [25-31] and tomography imaging $[32,33]$ is now commonly used to identify the micrometer and even sub-micrometer deformation and fracture mechanisms in mineralized tissues. Typical in situ x-ray synchrotron tomography experiments involve the irradiation of, for example, bone samples at a rate of $\sim 100 \mathrm{~Gy} / \mathrm{s}^{1}$. Corresponding exposures for in situ small angle x-ray scattering (SAXS) experiments of bone are much lower, typically at $\sim 0.2 \mathrm{~Gy} / \mathrm{s}^{2}$. The key parameters here are the flux density that can change by three orders of magnitude depending on the synchrotron source and the exposure time that can span from few seconds for in situ SAXS experiments to few hours for tomography scans; this leads to typical radiation doses ranging from $~ 1 \mathrm{~Gy}$ to as high as $1 \mathrm{MGy}$ (Table 1). In light of the aforementioned studies on gamma radiation, it is clear that the effect on the inherent properties of the tissue of such irradiation during in situ testing with synchrotron and desktop x-radiation sources data must be documented if the results of such experiments are to have any credence.

In this work, we examine how x-ray irradiation affects the deformation and fracture properties of human cortical bone. Such mechanical behavior in bone is a function of

\footnotetext{
${ }^{1}$ The rate of $100 \mathrm{~Gy} / \mathrm{s}$ is based on the specifications of the tomography beamline at the Advanced Light Source at the Lawrence Berkeley National Laboratory, assuming a sample thickness of $2 \mathrm{~mm}$, an incident $\mathrm{x}$-ray energy of $20 \mathrm{keV}$ with flux density of $2.1 \times 10^{5} \mathrm{photons} / \mathrm{s} / \mu \mathrm{m}^{2}$. For details, see Appendix.

${ }^{2}$ The rate $0.2 \mathrm{~Gy} / \mathrm{s}$ is based on the specifications from the SAXS beamline at the DESY Laboratory (see http://hasylab.desy.de/facilities/doris iii/beamlines/a2/beamline/index eng.html).
} 
the multi-dimensional hierarchical nature of its structure [34-38]; indeed, bone derives its resistance to fracture from a multitude of deformation and toughening mechanisms at many length-scales (Fig. 1), ranging from the nanoscale structure of its protein molecules to the macroscopic physiological scale of tubular bone structure [39,40]. These mechanisms can be classified as "plasticity" mechanisms which operate principally at sub-micrometer length-scales to promote intrinsic toughness ${ }^{3}$, involving molecular uncoiling of collagen molecules, fibrillar sliding of mineralized collagen fibrils and fibers and microcracking, and crack-tip shielding mechanisms which operate at larger length-scales to promote extrinsic toughness via such mechanisms as crack deflection and bridging. We show here that x-ray irradiation doses ranging from 70 kGy to 630 kGy deleteriously affect these mechanisms, we believe by primarily suppressing the intrinsic "plasticity" mechanisms at the sub-micrometer level, as characterized by the changes in the collagen environment seen with ultraviolet resonance Raman spectroscopy. The result is a major progressive loss in the mechanical integrity of the bone, specifically in its strength, post-yield ductility (strain) and toughness, with increasing levels of irradiation, to an extent that calls into question the use of in situ x-ray radiation to study the mechanical properties of biological tissue such as bone.

\footnotetext{
${ }^{3}$ Intrinsic toughening mechanisms operate ahead of the crack tip to generate resistance to microstructural damage. The most prominent mechanism is that of plastic deformation which provides a means of blunting the crack tip through the formation of "plastic" zones. Extrinsic toughening mechanisms, conversely, operate primarily in the wake of the crack tip to inhibit cracking by "shielding" the crack from the applied driving force [41-44]. Whereas intrinsic toughening mechanisms are effective in inhibiting both the initiation and growth of cracks, extrinsic mechanisms, e.g., crack bridging, are only effective in inhibiting crack growth [42].
} 


\section{EXPERIMENTAL METHODS}

\subsection{Materials}

Test samples from the midsection of frozen human cadaveric femoral cortical bone (48 year old) were sectioned using a low-speed saw and machined into thirty five bend samples $(N=35)$. The rectangular samples had a thickness $B$ of $1.5-2.0 \mathrm{~mm}$, a width $W$ of 3-4 $\mathrm{mm}$, and a length of $10 \mathrm{~mm}$. All samples were taken from locations longitudinal to the bone long axis. The samples were further divided into five groups of seven samples $(N=7)$ : one control group (non-irradiated), and four groups irradiated at $0.05,70,210$, and $630 \mathrm{kGy}$, respectively. X-ray irradiation was performed at the Advanced Light Source synchrotron facility at the Lawrence Berkeley National Laboratory on a superbend source. The low irradiation dose $(0.05 \mathrm{kGy})$ was achieved with a $10 \mathrm{~mm}$ thick aluminum shield during a two-bunch mode. The three high levels of irradiation were all achieved at $21 \mathrm{keV}$ in top-off mode and $500 \mathrm{~mA}$. The dose rate at the high level dose was $110 \mathrm{~Gy} / \mathrm{s}$ resulting in $70 \mathrm{kGy}$ for 10 mins exposure, $210 \mathrm{kGy}$ for 30 mins exposure, and $630 \mathrm{kGy}$ for 90 mins exposure (see Appendix for radiation calculations). These periods of time were selected in order to achieve multiple levels of irradiation doses typical of those received during sterilization (70 kGy) or during a typical scan time for a tomographic data set (30 to 90 mins). All samples were kept hydrated during irradiation.

Three $(N=3)$ samples of each group were used for three-point bending tests, and the remaining four samples $(N=4)$ of the group were used for crack resistance-curve ( $R$ curve) measurements. ${ }^{4}$ R-curve measurements were performed on single-edge notched

\footnotetext{
${ }^{4}$ The crack resistance- or R-curve provides an assessment of the fracture toughness in the presence of subcritical crack growth. It involves measurements of the crack-driving force, e.g., the stress intensity $K$, strain-energy release rate $G$ or J-integral, as a function of crack extension $(\Delta a)$. The value of the driving force at $\Delta a \rightarrow 0$ provides a measure of the crack-initiation toughness whereas the slope and/or the maximum value of the R-curve can be used to characterize the crack-growth toughness.
} 
bend, SE(B), specimens. The initial notch was formed initially with a low-speed diamond saw; it was then subsequently sharpened by repeatedly sliding a razor blade over the saw-cut notch, while continually irrigating with $1 \mu \mathrm{m}$ diamond slurry. The final micro-notches had a root radius of $\sim 3-5 \mu \mathrm{m}$. Using this technique, sharp cracks with initial crack length, $a \approx 1.5-2.0 \mathrm{~mm}(a / W \approx 0.5)$, were generated in general accordance with ASTM standards [45]. The orientation of the notch was such that the nominal crack-growth direction was perpendicular to the long axis of the bone (transverse orientation). Prior to testing, all samples were wet polished with an increasingly higher finish to a final polish with a $0.05 \mu \mathrm{m}$ diamond suspension before being immersed in ambient Hanks' balanced saline solution (HBSS) for $24 \mathrm{hr}$.

\subsection{Strength, toughness and J-R curve measurements}

Three-point bend tests were performed to generate quantitative stress-strain curves. The strength tests were performed on unnotched bend specimens using a support span $S$ of $7.5 \mathrm{~mm}$ and a displacement rate of $10 \mu \mathrm{m} / \mathrm{s}$. From these measurements, the ultimate bending stress and strain were determined at the point of maximum load. In addition, the bending stiffness was calculated from the slope of the stress/strain curves, and the work-of-fracture calculated from the area under these curve divided by twice the cross-sectional area of the fracture surface.

In order to capture both intrinsic (plasticity) and extrinsic (shielding) toughening mechanisms acting in the irradiated bone, fracture toughness measurements were performed using nonlinear-elastic fracture mechanics methods, specifically involving the J-integral5; in contrast to linear-elastic methods, e.g., using the stress intensity $K$, these methods provide a more realistic description of the contribution to the toughness

${ }^{5} \mathrm{~J}$ is the nonlinear strain-energy release rate, i.e., the rate of change in potential energy for a unit increase in crack area in a nonlinear elastic solid. It is the nonlinear-elastic equivalent of the strain-energy release rate $G$. It characterizes the stress and displacement fields at a crack tip in such a solid, and as such can be used to define the onset of fracture there. 
from the energy consumed in plastic deformation ${ }^{6}$ prior to, and during, fracture [46-48]. $J-R$ curves were performed under rehydrated conditions in mode I (tensile-opening) using $\mathrm{SE}(\mathrm{B})$ specimens with a crack-growth direction transverse to the long axis of the osteons (transverse orientation). R-curves were measured on HBSS-saturated specimens in situ in a Hitachi S-4300SE/N environmental scanning electron microscope (ESEM) using a Gatan Microtest three-point bending stage. Crack extension was monitored directly in back-scattered electron mode at a pressure of $35 \mathrm{~Pa}$ and a $30 \mathrm{kV}$ excitation voltage. Tests were conducted in three-point bending with a span $(S=6 \mathrm{~mm})$ to width ( $W=3 \mathrm{~mm}$ ) ratio of $\sim 2$, in accordance with ASTM Standard E1820-08 [45]. R-curve tests were terminated after $\sim 700 \mu \mathrm{m}$ of crack extension; the samples that had not failed at this stage were stored for subsequent tomography analysis.

Measured R-curve data points were limited to small-scale bridging conditions, where the size of the zone of crack bridges behind the crack tip remained small compared to the in-plane test specimen dimensions. As noted above, the use of the Jintegral as the driving force for crack initiation and growth was employed to capture the contribution from inelastic deformation in the evaluation of toughness. The stress intensity at each measured crack length was calculated by measuring the nonlinear strain-energy release rate, $J$. The value of $J$ was calculated from the applied load and instantaneous crack length according to ASTM standards [45], and was decomposed into its elastic and plastic contributions:

$$
J=J_{\text {el }}+J_{\mathrm{pl}} .
$$

The elastic contribution Jel is based on linear-elastic fracture mechanics:

\footnotetext{
6 Plastic deformation here is used as a general term to indicate any of the inelastic, non-recoverable deformation mechanisms, such as local collagen fibrillar shearing, viscoplasticity, and microcracking, that are active at various length-scales in bone [39,40].
} 


$$
J_{\mathrm{el}}=\frac{K_{\mathrm{I}}^{2}}{E},
$$

where $K_{\mathrm{I}}$ is the mode I stress-intensity factor, and $E$ is the Young's modulus. Using the load-line displacements, the plastic component $J_{\mathrm{pl}}$ for a stationary crack in bending is given by:

$$
J_{\mathrm{pl}}=\frac{1.9 A_{\mathrm{pl}}}{B b},
$$

where $A_{\mathrm{pl}}$ is the plastic area under force $v$ s. displacement curve, $b$ is the uncracked ligament length $(W-a) . K$-based fracture toughness $K_{\mathrm{Jc}}$ values were back-calculated from the $J$ measurements using the standard $J-K$ equivalence for nominally mode I fracture, specifically that $K_{\mathrm{Jc}}=\left(J_{\mathrm{c}} E\right)^{1 / 2}$, with the Young's modulus taken as $20 \mathrm{GPa}$.

For all fracture toughness tests conducted, conditions for $J$-dominance, as specified by the active ASTM standard [45], were met, i.e., $b, B>>10\left(J_{c} / \sigma_{y}\right)$, where $\sigma_{y}$ is the flow stress. This latter criterion ensures that the critical $J_{c}$ (and calculated $K_{\mathrm{Jc}}$ ) values represent valid fracture toughness values.

\subsection{Deep-ultraviolet Raman spectroscopy}

To measure vibrational spectra, deep-ultraviolet Raman spectroscopy, with a 244$\mathrm{nm}$ excitation source was used to evaluate irradiation-related changes in the structure of bone at the molecular level [49]. The UV Raman technique eliminates the fluorescence interference found with visible excitation. Also, due to resonance effects, the signal strength of some features from the organic phase (particular those associated with the amide moiety formed by the bonds between peptides) are enhanced relative to those from the inorganic phase (e.g., phosphate and carbonate stretching modes). To avoid damage to the sample the laser power was kept below $5 \mathrm{~mW}$ and the sample was rotated at approximately $45 \mathrm{rpm}$. We have previously shown $[49,50]$ that the height of 
the amide I feature at $1650 \mathrm{~cm}^{-1}$ is sensitive to the collagen environment, increasing, for example, with dehydration or with increasing tissue age. For quantitative analysis of this effect, spectra were processed by subtracting a small linear background defined by the signal at 500 and $2000 \mathrm{~cm}^{-1}$ and then normalizing to the height of the $\mathrm{CH}_{2}$ wag peak at $1460 \mathrm{~cm}^{-1}$ (this peak does not have a strong resonance enhancement).

\subsection{Microstructural characterization}

The microstructure of bone was characterized using scanning electron microscopy in the back-scattered electron mode with the Hitachi S-4300SE/N ESEM. Synchrotron xray computed micro-tomography $(\mu \mathrm{XCT})$ was employed to visualize in threedimensions the crack path and distribution of micro-damage after $R$-curve testing. The $\mu \mathrm{XCT}$ evaluation was performed at the Advanced Light Source synchrotron radiation facility at Lawrence Berkeley National Laboratory; the setup is similar to standard tomography procedures [51] in that samples are rotated in a monochromatic x-ray beam and the transmitted $\mathrm{x}$-rays imaged via a scintillator, magnifying lens and a digital camera to give an effective voxel size in the reconstructed three-dimensional image of $1.8 \mu \mathrm{m}$. Samples were scanned in absorption mode and the reconstructed images were obtained using a filtered back-projection algorithm. In absorption mode, the gray scale values of the reconstructed image are representative of the absorption coefficient. To maximize the signal-to-noise ratio, an energy of $20 \mathrm{keV}$ was selected; this optimizes the interaction between the x-rays and the sample. Two-dimensional images were taken every quarter of a degree between 0 and 180 degrees. The data sets were then reconstructed using the software Octopus [52] and the three-dimensional visualization was performed using Avizo $^{\mathrm{TM}}$ software [53]. 


\section{RESULTS}

\subsection{Strength and fracture toughness}

Bending stress-strain curves (Fig. 2a) and fracture toughness R-curves (Fig. 2b) both show a major dose-dependent degradation of the mechanical properties of bone after $\mathrm{x}$ ray irradiation. Data are tabulated in Table 2. With increasing radiation doses up to $630 \mathrm{kGy}$, a marked reduction was seen in the ultimate (maximum) bending strength and bending strain, together with the work-to-fracture (Fig. 3a), although little change was found in the bending stiffness. The strength of the bone decreased by $\sim 25 \%, 60 \%$ and more than $80 \%$ as the irradiation dose was raised, respectively, from $70 \mathrm{kGy}$ to $210 \mathrm{kGy}$ and $630 \mathrm{kGy}$; a similar trend was observed for the ultimate strain (Fig. 3a). No significant degradation in the mechanical properties was observed at the smallest dose of $0.05 \mathrm{kGy}$. Noting that it is here difficult to identify a threshold due to the lack of irradiation data in the 0.05-70 kGy range, the most dramatic effect was seen above an irradiation dose of $70 \mathrm{kGy}$, where the bone displayed no evidence at all of post-yield plastic deformation. Additionally, the work-to-fracture decreased by $70 \%$ to almost $100 \%$ as the irradiation dose increased from 70 to $630 \mathrm{kGy}$ (Fig. 3a). These observations are consistent with reports $[6,8-10,12,13,19]$ of the significant effect of gamma irradiation on the plastic properties such as the bending strength and toughness, rather than the elastic properties such as stiffness and elastic limit. Of importance is that although the irradiation doses in question are very large compared to the few second exposures typical of in situ x-ray scattering experiments, they are definitely comparable to the irradiation associated typical tomography imaging runs (Table 1),

Full $K_{\mathrm{R}}(\Delta a)$ resistance curves determined for physiologically-relevant small cracks $(\Delta a<700 \mu \mathrm{m})$ are shown in Fig. $2 \mathrm{~b}$. It is interesting to note that all irradiated samples exhibit a rising R-curve behavior indicative of stable crack growth before fracture, even after large $210 \mathrm{kGy}$ doses, despite the complete loss of "plasticity". This indicates that 
principal extrinsic crack-tip shielding mechanisms which toughen bone, i.e., crack bridging and crack deflection/twist, remain active behind the crack tip after severe irradiation to locally screen the crack from the applied (far-field) driving force. However, the R-curves (Fig. 2b) still give a clear indication that prior irradiation causes both the crack-initiation toughness (assessed in terms of the intercept of the R-curve at $\Delta a \rightarrow 0, K_{\mathrm{o}}$ ) and crack-growth toughness (assessed as both the slope of the R-curve, $\mathrm{d} K / \mathrm{d} \Delta a$ and the instability toughness value, $K_{\mathrm{Jc}}$ ) to significantly decrease with irradiation dose (Fig. 3b). Similar behavior has been observed with the aging of human cortical bone [54,55], as discussed below.

For the first $600 \mu \mathrm{m}$ of crack extension (Fig. 2b), $K_{\mathrm{Jc}}$ fracture toughness values were as much as a factor of five lower after $210 \mathrm{kGy}$ irradiation, i.e., $13.3 \mathrm{MPa} \sqrt{\mathrm{m}}\left(\mathrm{J}_{\mathrm{c}} \sim 9 \mathrm{~kJ} / \mathrm{m}^{2}\right)$ in the unirradiated samples down to $2.7 \mathrm{MPa} \vee_{\mathrm{m}}\left(\mathrm{J}_{\mathrm{c}} \sim 0.3 \mathrm{~kJ} / \mathrm{m}^{2}\right)$ in the $210 \mathrm{kGy}$ irradiated

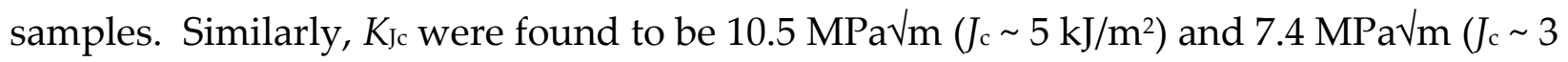
$\mathrm{kJ} / \mathrm{m}^{2}$ ) for the respective 50 Gy and $70 \mathrm{kGy}$ irradiated samples.

\subsection{Crack-growth observations}

The associated mechanistic sources of toughening in irradiated bone were identified during the in situ mechanical tests in the environmental scanning electron microscope on rehydrated samples. This technique provides the opportunity to measure quantitatively the $R$-curve while simultaneously monitoring the evolution of damage mechanisms ahead of the growing crack and the toughening mechanisms that result in its wake; furthermore, how these mechanisms relate to the bone architecture can be imaged in real time (Fig. 4a,d).

Results show that the extrinsic toughening mechanisms in bone, i.e., the crack deflection/twist and crack bridging processes that operate at length-scales above a micrometer $[47,56]$, are still operative in the irradiated bone; accordingly, all samples displayed subcritical (stable) crack growth over the initial $700 \mu \mathrm{m}$ of crack extension 
(Fig. 2b). These mechanisms result from the occurrence of microcracking primarily along the cement lines, i.e., the "weaker" hyper-mineralized interfaces of the osteons, and to a lesser extent along the lamellar boundaries. The growing cracks deflect by as much as 90 degrees as they encounter these interfaces between the interstitial bone and the osteons, leading to the marked crack deflections and through-thickness twists (Fig. 4) that are the primary source of (extrinsic) toughening in the transverse orientation. Although prior irradiation does not inhibit these mechanisms, SEM and $\mu$ XCT imaging shows that the frequency of deflection appears to be greater in the irradiated samples (c.f., Figs. 4a \& d). As this leads to smaller-amplitude crack deflections (c.f., Figs. $4 \mathrm{~b} \&$ e, $4 c \& f)$, the extent of crack meandering within the bone-matrix is actually lower after irradiation, which is consistent with the crack extending at much lower stress intensities.

\subsection{Raman spectroscopy}

Deep-UV Raman spectra for 0, 0.05, 70, and $210 \mathrm{kGy}$ doses are shown in Fig 5. The main peaks observed in the control sample are indicated: amide III (from in-phase combination of NH in-plane bend and $\mathrm{CN}$ stretch, c. 1245-1260 cm-1), $\mathrm{CH}_{2}$ wag (c. 1454$1461 \mathrm{~cm}^{-1}$ ), amide II (c. $1560 \mathrm{~cm}^{-1}$ ), Y8a (from tyrosine side chains at $1610 \mathrm{~cm}^{-1}$ ) and amide I (from $\mathrm{C}=\mathrm{O}$ stretch, $c$. 1626-1656 $\mathrm{cm}^{-1}$ ). The main change in the spectra of the irradiated samples is a monotonic increase (relative to the $\mathrm{CH}_{2} \mathrm{wag}$ ) of the amide I band, as shown in Table 3. We have previously observed increases in the amide I peak with dehydration and increasing age and have attributed them to broadening of the resonance profile for the amide $\pi \rightarrow \pi^{*}$ transition caused by changes in the intrafibrallar environment of the collagen molecules [49,50]. Here, we believe that the increase is due to increased collagen cross-linking induced by the radiation damage, as similarly reported for gamma radiation studies [15-17]. Finally, we note that at a dose of 630 $\mathrm{kGy}$, the spectral features were broadened to an extent such that the individual peaks 
could not be observed. This likely is due to breaking of peptide bonds in the collagen backbone.

\section{DISCUSSION}

This experimental study highlights a major deleterious effect of $\mathrm{x}$-ray radiation on "bone quality" for human cortical bone. For radiation dosage levels typical of in situ xray tomography imaging, we report a progressive decrease in both the post-yield mechanical properties (ultimate bending strength and strain) and fracture toughness (work-of-fracture and the crack-initiation and -growth toughness) with increase in irradiation levels from 0.05 to $630 \mathrm{kGy}$ (Figs. 2-5). The effects are not trivial; bending strengths decline by up to $\sim 100 \%$ and $K_{\mathrm{Jc}}$ fracture toughness values by a factor of five (Table 2). Structurally, the irradiation affects the collagen environment by increasing the degree of cross-linking, resulting in a total loss in post-yield (plastic) deformation leading to a radical decline in strength and ductility; this loss in intrinsic toughening, coupled with lower extrinsic toughening due to "smoother" crack paths, can be further associated with the large decline in fracture resistance (or toughness).

To understand the origin of this effect and specifically how irradiation can degrade the strength and toughening mechanisms in bone, we note that the fracture resistance of bone is a multiple-scale process with each level of structural hierarchy adapted to provide optimal toughness. Traditionally, toughness has been thought of as the ability of a material to dissipate deformation energy without propagation of a crack. However, fracture is actually the result of a mutual competition of intrinsic damage mechanisms ahead of the crack tip that promote cracking and extrinsic shielding mechanisms mainly behind the tip that impede it $[42,44]$. We thus consider the influence of irradiation in terms of how it may affect these two mechanistic components. 
At micro- to macro-scale dimensions, the toughness of cortical bone is dominated by the extrinsic contributions and associated with crack-tip shielding principally from crack bridging and deflection. The main structural feature controlling these mechanisms is the secondary osteons [57], or more precisely their interfaces, the cement lines [58], which act as prime locations for microcracking $[47,59,60]$. In the longitudinal orientations, such microcracking occurs nominally ahead and/or parallel to the main growth crack; the intact regions in between then act as ("uncracked-ligament") bridges which enhance the toughness by carrying load that would otherwise be used to propagate the crack $[47,56]$. In the presently tested transverse orientation, microcracking is conversely nominally orthogonal to the path of the main growing crack; the resulting crack arrest and "delamination" along the cement lines as the crack encounters the osteons (see Fig. 4) results in even more potent toughening in the form of crack deflection and twisting [46-48]. Our results show that loss of post-yield (plastic) deformation due to irradiation definitely diminishes this crack-growth toughness (Fig. 2b), although mechanistically, toughening via crack deflection/twist is still prevalent in the irradiated as well as the unirradiated samples (Fig. 4). However, as Fig. 4 illustrates, due to the increased frequency but decreased magnitude of the crack deflections, crack paths in irradiated samples are considerably less tortuous. Because the motion of a crack away from the path of maximum driving force, e.g., the Gmax path $[47,59,60]$, reduces the local stress intensity actually experienced at the crack tip, such less meandering crack trajectories in irradiated samples would certainly lessen the potency of the crack deflection toughening mechanism, thereby degrading the toughness with respect to unirradiated bone.

At sub-micrometer dimensions, toughening mechanisms in bone are largely intrinsic and, as noted above, can be classified as mechanisms of plastic deformation, involving processes such as molecular uncoiling and fibrillar sliding of collagen [39,40] (Fig. 1). 
These mechanisms contribute to the fracture toughness of bone by forming "plastic zones" around crack-like defects, thereby protecting the integrity of the entire structure by allowing for localized failure through energy dissipation. Clearly irradiation has a major effect in depriving bone of its ability to plastically deform, as evidenced by the dramatic and progressive loss in bending strength and ductility (strain to failure) with increasing x-ray dosage (Figs. 2a, 3a). Parallel Raman spectroscopy studies show this to be related to detrimental changes to the collagen environment (Fig. 5). In general, the integrity of the collagen molecules and the concentration of cross-links in between these molecules are the dominant factors affecting the collagen network in bone [61]. It is well documented that this can be severely affected by radiation. In particular, the majority of damage from gamma radiation is induced in bone by the radiolysis of water molecules which generate free radicals which in turn target bonds within the collagen structure [62, 63], resulting in cross-linking reactions in the collagen molecules [15-17]. Collagen is the primary target for such radiation-induced free radical attack because of the significant amount of water bound to its structure $[17,64]$. Indeed, most of the in vivo and in vitro damage to biological systems from gamma radiation can be attributed to the hydroxyl $(\mathrm{OH}-)$ free radical $[63,65,66]$. These free radicals react with target collagen molecules within a lifetime on the order of 0.01-1 ns and render irrecoverable changes in the chemical structure of the collagen [62]. The question then arises how such irradiation-induced changes to the collagen can specifically affect plasticity.

Mineralized collagen fibrils are the basic building blocks of the bone matrix; they consist of a self-assembly of tropocollagen (TC) molecules, which individually consist of three polypeptides arranged in triple-helical "nanoropes". The nanoropes are stabilized by hydrogen bonding between residues [67-69]; every third residue in each of the molecules is the amino acid glycine (GLY) and about one fourth of the TC molecule consists of proline and hydroxyproline [70,71]. At this length-scale, bone deforms by 
stretching and unwinding of individual collagen molecules due first to entropic and then energetic mechanisms that involve H-bond breaking $[39,40]$. Within the fibrils, such molecular stretching competes with intermolecular sliding and breaking of weak and strong bonds between TC molecules, both sliding motions provide the basis for large plastic strains without catastrophic failure. ${ }^{7}$ At the mineralized collagen fibril level, continuous glide between TC molecules and between hydroxyapatite (HA) particles and these molecules, initiated by slip at the HA-TC molecule interface, enables a large regime of dissipative deformation once plastic yielding begins. Such molecular behavior of the protein and mineral phases during large-scale deformation of the mineralized collagen fibrils, in addition to representing a mechanism of plasticity, provides for intrinsic toughening and enhanced fracture resistance through the formation of plastic zones around crack-like defects [77,78]. As noted above, radiationinduced free radical attack of the collagen network results in a cross-linking reaction that degrades the structural integrity of the collagen fibers [16,17], and most likely restricts the fibrillar sliding (plasticity) mechanisms. Consequently, any degradation of the collagen molecules, e.g., by irradiation, that acts to restrict these plasticity/intrinsic toughening mechanisms in bone would limit ductility, reduce strength and lower toughness.

Besides such radiation-induced embrittlement of bone, similar effects of altered collagen biochemistry have been reported to cause increased fragility in bone due to aging $[54,79]$ and disease $[80,81]$. For example, a significant reduction in the crackinitiation toughness and an almost complete elimination of crack-growth toughness in human cortical bone has been observed with increasing age [54], effects that have

\footnotetext{
7 Severe mechanical tensile loading of collagen is significant under physiological conditions. Through such sliding mechanisms, it has the ability to stretch up to $50 \%$ tensile strain before breaking while reaching force levels of more than $10 \mathrm{nN}$ per molecule (or to a stress of 10-20 GPa stress after normalization by the cross-sectional area of the molecule) [72-76].
} 
similarly been attributed at the sub-micrometer scale to increased cross-linking and deterioration in the collagen and at the micrometer scale and above to reduced extrinsic toughening from degraded crack-tip shielding [54,57].

This is even more evident from the fact that structural alterations, or mutations in the collagen gene, can lead to severe diseases that are associated with a severe deterioration of the mechanical properties of bone. One of the most well known genetic diseases is osteogenesis imperfect (brittle bone disease), where tiny single point mutations (i.e. molecular defects at the level of single amino acids, or a few Ångstrom in lengthscale) in the collagen type I gene leads to mechanical weakness at larger scales $[82,83]$ due to a softening of the tropocollagen molecule's stiffness and a significant reduction of the intermolecular adhesion [84,85]. This example shows that under disease conditions, the intrinsic repair and toughening mechanisms of bone can fail to function properly and lead to a rapid breakdown of the tissue [86].

\section{CONCLUDING REMARKS}

Many in situ mechanical tests require long data acquisition times and use x-rays with extremely high flux density. For biological tissue such as bone, we have shown here that such exposure to high levels of irradiation can cause serious deleterious effects to the collagen which leads to drastic losses in strength, ductility and toughness. It is therefore essential that studies using in situ radiation, such as deformation and fracture testing coupled with x-ray diffraction and/or tomography, carefully take this into consideration. For in situ high-energy x-ray diffraction studies, the crucial factor is the amount of time that the sample is exposed, since the radiation flux levels are fairly low and generally fall in the "non-damaging" dose range. As such times are typically only a few seconds, irradiation-damage is generally not much of an issue with these techniques. For in situ x-ray tomography studies, however, the irradiation levels are 
much higher and the required exposure times to gain accurate information about a sample are typically 30 minutes of more, even on a synchrotron. Here the potential for severe tissue damage during the experiment is far more likely. Indeed, we would question the results of any in situ mechanical studies that involve concurrent $\mathrm{x}$-ray tomography at irradiation levels of higher than $35 \mathrm{kGy}$, which with a standard $20 \mathrm{keV}$ x-ray tomography beamline would be achieved after exposure times of only 5 minutes or so. It is therefore imperative to carefully evaluation the irradiation dose level for any in situ high energy $\mathrm{x}$-ray study on biological materials to ascertain that the radiation will not lead to severely altered properties of the tissue.

\section{CONCLUSIONS}

Based on an experimental study on the effect of irradiation by x-rays of the mechanical behavior of hydrated human cortical bone (in the transverse orientation), the following specific conclusions can be made:

1. Exposure to synchrotron x-ray irradiation doses of between 0.05 and $630 \mathrm{kGy}$ progressively led to a major deterioration in the mechanical properties. Specifically, after $630 \mathrm{kGy}$ of radiation, the ultimate bending strength and ductility (fracture strain) of the bone were decreased by $\sim 80 \%$, the work-of-fracture by almost $100 \%$, and the $K_{\mathrm{Jc}}$ fracture toughness by a factor of five.

2. Even doses as low as $70 \mathrm{kGy}$ resulted in losses in bone strength and the work-offracture by as much as 25 and $70 \%$, respectively.

3. Macroscopically, bone exposed to irradiation doses of $70 \mathrm{kGy}$ and above displayed a complete absence of post-yield plastic deformation.

4. UV Raman spectroscopy revealed a significant increase in the amide-I peak with increase in irradiation exposure, indicating a change in the collagen environment. 
This was associated with an increase in cross-linking in the collagen, consistent with the decline in the bone's capacity for plastic deformation.

5. J-integral resistance-curve measurements also revealed a marked degradation in fracture toughness, both for crack initiation and crack growth, with increasing exposure to x-rays. Mechanistically, this was associated both with diminished intrinsic toughening, from the limited plasticity in irradiated bone, and diminished extrinsic toughness due to a smaller contribution from crack deflection toughening from less tortuous crack paths in irradiated bone.

6. This work implies that the results from in situ experimental research on biological materials that use a radiation source must be considered with care. Whereas typical irradiation exposures for in situ x-ray micro-diffraction studies on bone are generally insignificantly small, the radiation doses examined in the present work are comparable with those typically used for in situ synchrotron x-ray tomography studies, which calls into question the veracity of results derived from such work.

\section{ACKNOWLEDGMENTS}

This work was supported by the Laboratory Directed Research and Development Program of Lawrence Berkeley National Laboratory (LBNL), funded by the U.S. Department of Energy under contract no. DE-AC02-05CH11231. We acknowledge the use of the x-ray synchrotron micro-tomography beam line (8.3.2) at the Advanced Light Source at LBNL, supported by the Office of Science of the Department of Energy. The authors also wish to thank Professor Tony M. Keaveny and Mike Jekir, of the Mechanical Engineering Department at the University of California, Berkeley, for graciously allowing us to use their facilities to machine samples for this project.

\section{REFERENCES}

[1] Baden JM, Brodsky JB. Pregnant Surgical Patient. London: Futura, 1985.

[2] Fideler BM, Vangsness CT, Moore T, Li ZL, Rasheed S. Effects of gammairradiation on the human immunodeficiency virus: A study in frozen human 
bone - patellar ligament - bone grafts obtained from infected cadavera. J. Bone Joint Surg.-Am. Vol. 1994;76A:1032.

[3] Association for the Advancement of Medical Instrumentation. AAMI/ISO111371, Sterilization of health care products-Radiation-Part 1: Requirements for the development, validation and routine control of a sterilization process for medical devices. Arlington, VA: Association for the Advancement of Medical Instrumentation, 2006.

[4] McAllister DR, Joyce MJ, Mann BJ, Vangsness CT. The current status of tissue regulation, procurement, processing, and sterilization. Am. J. Sports Med. 2007;35:2148.

[5] Kennedy JF, Phillips GO, Williams PA. Sterilisation of tissues using ionizing radiations. Boca Raton, Florida: CRC Press LLC, 2005.

[6] Anderson MJ, Keyak JH, Skinner HB. Compressive mechanical-properties of human cancellous bone after gamma irradiation. J. Bone Joint Surg.-Am. Vol. 1992;74A:747.

[7] Cornu O, Banse X, Docquier PL, Luyckx S, Delloye C. Effect of freeze-drying and gamma irradiation on the mechanical properties of human cancellous bone. J. Orthop. Res. 2000;18:426.

[8] Currey JD, Foreman J, Laketic I, Mitchell J, Pegg DE, Reilly GC. Effects of ionizing radiation on the mechanical properties of human bone. J. Orthop. Res. 1997;15:111.

[9] Gibbons MJ, Butler DL, Grood ES, Bylskiaustrow DI, Levy MS, Noyes FR. Effects of gamma irradiation on the initial mechanical and material properties of goat bone - patellar tendon - bone allografts. J. Orthop. Res. 1991;9:209.

[10] Hamer AJ, Strachan JR, Black MM, Ibbotson CJ, Stockley I, Elson RA. Biomechanical properties of cortical allograft bone using a new method of bone strength measurement - A comparison of fresh, fresh-frozen and irradiated bone. J. Bone Joint Surg.-Br. Vol. 1996;78B:363.

[11] Vastel L, Meunier A, Siney H, Sedel L, Courpied JP. Effect of different sterilization processing methods on the mechanical properties of human cancellous bone allografts. Biomaterials 2004;25:2105.

[12] Fideler BM, Vangsness T, Lu B, Orlando C, Moore T. Gamma irradiation effects on biomechanical properties of human bone - patellar tendon - bone allografts. Am. J. Sports Med. 1995;23:643. 
[13] Salehpour A, Butler DL, Proch E, Schwartz HE, Feder SM, Doxey CM, Ratcliffe A. Dose-dependent response of gamma irradiation on mechanical properties and related biochemical composition of goat bone-patellar tendon-bone allografts. J. Orthop. Res. 1995;13:898.

[14] Smith CW, Young IS, Kearney JN. Mechanical properties of tendons: Changes with sterilization and preservation. J. Biomech. Eng.-Trans. ASME 1996;118:56.

[15] Colwell A, Hamer A, Blumsohn A, Eastell R. To determine the effects of ultraviolet light, natural light and ionizing radiation on pyridinium cross-links in bone and urine using high-performance liquid chromatography. Eur. J. Clin. Invest. 1996;26:1107.

[16] Nguyen H, Morgan DA, Forwood MR. Sterilization of allograft bone: effects of gamma irradiation on allograft biology and biomechanics. Cell Tissue Banking 2007;8:93.

[17] Akkus O, Belaney RM, Das P. Free radical scavenging alleviates the biomechanical impairment of gamma radiation sterilized bone tissue. J. Orthop. Res. 2005;23:838.

[18] Akkus O, Belaney RM. Sterilization by gamma radiation impairs the tensile fatigue life of cortical bone by two orders of magnitude. J. Orthop. Res. 2005;23:1054.

[19] Hamer AJ, Stockley I, Elson RA. Changes in allograft bone irradiated at different temperatures. J. Bone Joint Surg.-Br. Vol. 1999;81B:342.

[20] Akkus O, Rimnac CM. Fracture resistance of gamma radiation sterilized cortical bone allografts. J. Orthop. Res. 2001;19:927.

[21] Balsly CR, Cotter AT, Williams LA, Gaskins BD, Moore MA, Wolfinbarger L. Effect of low dose and moderate dose gamma irradiation on the mechanical properties of bone and soft tissue allografts. Cell Tissue Banking 2008;9:289.

[22] Zhang YX, Homsi D, Gates K, Oakes K, Sutherland V, Wolfinbarger L. A comprehensive study of physical parameters, biomechanical properties, and statistical correlations of iliac crest bone wedges used in spinal fusion surgery. IV: effect of gamma irradiation on mechanical and material properties. Spine 1994;19:304.

[23] Grieb T, Forng RY, Brown R, Owolabi T, Maddox E, McBain A, Drohan WN, Mann DM, Burgess WH. Effective use of gamma irradiation for pathogen inactivation of monoclonal antibody preparations. Biologicals 2002;30:207. 
[24] Muller R. Hierarchical microimaging of bone structure and function. Nat. Rev. Rheumatol. 2009;5:373.

[25] Akhtar R, Daymond MR, Almer JD, Mummery PM. Elastic strains in antler trabecular bone determined by synchrotron X-ray diffraction. Acta Biomater. 2008;4:1677.

[26] Gupta HS, Messmer P, Roschger P, Bernstorff S, Klaushofer K, Fratzl P. Synchrotron diffraction study of deformation mechanisms in mineralized tendon. Phys. Rev. Lett. 2004;93:4.

[27] Gupta HS, Wagermaier W, Zickler GA, Aroush DRB, Funari SS, Roschger P, Wagner HD, Fratzl P. Nanoscale deformation mechanisms in bone. Nano Lett. 2005;5:2108.

[28] Krauss S, Fratzl P, Seto J, Currey JD, Estevez JA, Funari SS, Gupta HS. Inhomogeneous fibril stretching in antler starts after macroscopic yielding: Indication for a nanoscale toughening mechanism. Bone 2009;44:1105.

[29] Gupta HS, Seto J, Wagermaier W, Zaslansky P, Boesecke P, Fratzl P. Cooperative deformation of mineral and collagen in bone at the nanoscale. Proc. Natl. Acad. Sci. U. S. A. 2006;103:17741.

[30] Deymier AC, Almer JD, Stock SR, Haeffner DR, Dunand DC. Synchrotron X-ray diffraction study of load partitioning during elastic deformation of bovine dentin. Acta Biomater.;In Press.

[31] Almer JD, Stock SR. Internal strains and stresses measured in cortical bone via high-energy X-ray diffraction. J. Struct. Biol. 2005;152:14.

[32] Thurner PJ, Wyss P, Voide R, Stauber M, Stampanoni M, Sennhauser U, Muller R. Time-lapsed investigation of three-dimensional failure and damage accumulation in trabecular bone using synchrotron light. Bone 2006;39:289.

[33] Voide R, Schneider P, Stauber M, Wyss R, Stampanoni M, Sennhauser U, van Lenthe GH, Muller R. Time-lapsed assessment of microcrack initiation and propagation in murine cortical bone at submicrometer resolution. Bone 2009;45:164.

[34] Jeronimidis G. In: Elices $M$, editor. Structural biological materials, design and structure-property relationships. Amsterdam: Pergamon, 2000. p.3.

[35] Fratzl P, Weinkamer R. Nature's hierarchical materials. Prog. Mater. Sci. 2007;52:1263.

[36] Meyers MA, Chen PY, Lin AYM, Seki Y. Biological materials: Structure and mechanical properties. Prog. Mater. Sci. 2008;53:1. 
[37] Rho JY, Kuhn-Spearing L, Zioupos P. Mechanical properties and the hierarchical structure of bone. Med. Eng. Phys. 1998;20:92.

[38] Weiner S, Wagner HD. The material bone: Structure mechanical function relations. Annu. Rev. Mater. Sci. 1998;28:271.

[39] Ritchie RO, Buehler MJ, Hansma PK. Plasticity and toughness in bone. Phys. Today 2009;62:41.

[40] Launey ME, Buehler MJ, Ritchie RO. On the mechanistic origins of toughness in bone. Ann. Rev. Mater. Res.;in review.

[41] Evans AG. Perspective on the development of high-toughness ceramics. J. Am. Ceram. Soc. 1990;73:187.

[42] Ritchie RO. Mechanisms of fatigue crack-propagation in metals, ceramics and composites: role of crack tip shielding. Mater. Sci. Eng., A 1988;103:15.

[43] Ritchie RO. Mechanisms of fatigue-crack propagation in ductile and brittle solids. Int. J. Fract. 1999;100:55.

[44] Launey ME, Ritchie RO. On the fracture toughness of advanced materials. Adv. Mater. 2009;21:2103.

[45] E1820-08 A. Annual Book of ASTM Standards, Vol. 03.01: Metals - Mechanical Testing; Elevated and Low-temperature Tests; Metallography. West Conshohocken, Pennsylvania, USA: ASTM International, 2008.

[46] Yan JH, Mecholsky JJ, Clifton KB. How tough is bone? Application of elasticplastic fracture mechanics to bone. Bone 2007;40:479.

[47] Koester KJ, Ager JW, Ritchie RO. The true toughness of human cortical bone measured with realistically short cracks. Nat. Mater. 2008;7:672.

[48] Launey ME, Chen PY, McKittrick J, Ritchie RO. Mechanistic aspects of fracture and R-curve behavior in elk antler bone. Acta Biomater.;in press.

[49] Ager JW, Nalla RK, Breeden KL, Ritchie RO. Deep-ultraviolet Raman spectroscopy study of the effect of aging on human cortical bone. J. Biomed. Opt. 2005;10:8.

[50] Ager JW, Nalla RK, Balooch G, Kim G, Pugach M, Habelitz S, Marshall GW, Kinney JH, Ritchie RO. On the increasing fragility of human teeth with age: A deep-UV resonance Raman study. J. Bone Miner. Res. 2006;21:1879.

[51] Kinney JH, Nichols MC. X-ray tomographic microscopy using synchrotron radiation. Annu. Rev. Mater. Sci. 1992;22:121. 
[52] Vlassenbroeck J, Dierick M, Masschaele B, Cnudde V, Hoorebeke L, Jacobs P. Software tools for quantification of X-ray microtomography. Nucl. Instrum. Methods Phys. Res., Sect. A 2007;580:442.

[53] Mercury CS. Avizo ${ }^{\mathrm{TM}}$ 3D Visualization Framework. Chelmsford, MA.

[54] Nalla RK, Kruzic JJ, Kinney JH, Ritchie RO. Effect of aging on the toughness of human cortical bone: evaluation by R-curves. Bone 2004;35:1240.

[55] Wu P-C, Vashishth D. Age-related changes in cortical bone toughness: initiation vs. propagation. Proc. Second Joint EMBS/BMES Conference. Houston, TX: IEEE, 2002. p.425.

[56] Nalla RK, Kinney JH, Ritchie RO. Mechanistic fracture criteria for the failure of human cortical bone. Nat. Mater. 2003;2:164.

[57] Nalla RK, Kruzic JJ, Kinney JH, Balooch M, Ager JW, Ritchie RO. Role of microstructure in the aging-related deterioration of the toughness of human cortical bone. Mater. Sci. Eng., C 2006;26:1251.

[58] Skedros JG, Holmes JL, Vajda EG, Bloebaum RD. Cement lines of secondary osteons in human bone are not mineral-deficient: New data in a historical perspective. Anat. Rec. Part A 2005;286A:781.

[59] Nalla RK, Stolken JS, Kinney JH, Ritchie RO. Fracture in human cortical bone: local fracture criteria and toughening mechanisms. J. Biomech. 2005;38:1517.

[60] Zimmermann EA, Launey ME, Barth HB, Ritchie RO. Mixed-mode fracture of human cortical bone. Biomaterials 2009;30:5877.

[61] Wang X, Shen X, Li X, Agrawal CM. Age-related changes in the collagen network and toughness of bone. Bone 2002;31:1.

[62] Halliwel B, Gutteridge JMC. Free radicals in biology and medicine. Oxford: Clarendon Press, 1989.

[63] Stadtman ER. Oxidation of free amino acids and amino acid residues in proteins by radiolysis and by metal-catalyzed reactions. Annu. Rev. Biochem 1993;62:797.

[64] Schreiner LJ, Cameron IG, Funduk N, Miljkovic L, Pintar MM, Kydon DN. Proton NMR spin grouping and exchange in dentin. Biophys. J. 1991;59:629.

[65] Hawkins CL, Davies MJ. Oxidative damage to collagen and related substrates by metal ion hydrogen peroxide systems: Random attack or site-specific damage? Biochim. Biophys. Acta 1997;1360:84.

[66] Ward JF. The yield of DNA double strand breaks produce intracellularly by ionizing radiation: A review. Int. J. Radiat. Biol. 1990;57:1141. 
[67] Ramachandran GN, Kartha G. Structure of collagen. Nature 1955;176:593.

[68] Canty EG, Kadler KE. Collagen fibril biosynthesis in tendon: a review and recent insights. Comp. Biochem. Physiol. A: Mol. Integr. Physiol. 2002;133:979.

[69] Kadler KE, Holmes DF, Trotter JA, Chapman JA. Collagen fibril formation. Biochem. J 1996;316:1.

[70] Prockop DJ, Kivirikko KI. Collagens: molecular biology, diseases, and potentials for therapy. Annu. Rev. Biochem 1995;64:403.

[71] Prockop DJ, Kivirikko KI. Heritable diseases of collagen. New Engl. J. Med. 1984;311:376.

[72] Sun YL, Luo ZP, Fertala A, An KN. Stretching type II collagen with optical tweezers. J. Biomech. 2004;37:1665.

[73] Buehler MJ. Nanomechanics of collagen fibrils under varying cross-link densities: Atomistic and continuum studies. J. Mech. Behav. Biomed. Mater. 2008;1:59.

[74] Buehler MJ. Atomistic and continuum modeling of mechanical properties of collagen: Elasticity, fracture, and self-assembly. J. Mater. Res. 2006;21:1947.

[75] Buehler MJ, Wong SY. Entropic elasticity controls nanomechanics of single tropocollagen molecules. Biophys. J. 2007;93:37.

[76] Gautieri A, Buehler MJ, Redaelli A. Deformation rate controls elasticity and unfolding pathway of single tropocollagen molecules. J. Mech. Behav. Biomed. Mater. 2009;2:130.

[77] Buehler MJ. Molecular nanomechanics of nascent bone: fibrillar toughening by mineralization. Nanotechnology 2007;18.

[78] Buehler MJ, Keten S, Ackbarow T. Theoretical and computational hierarchical nanomechanics of protein materials: Deformation and fracture. Prog. Mater. Sci. 2008;53:1101.

[79] Zioupos P, Currey JD, Hamer AJ. The role of collagen in the declining mechanical properties of aging human cortical bone. J. Biomed. Mater. Res. 1999;45:108.

[80] Jepsen KJ, Schaffler MB, Kuhn JL, Goulet RW, Bonadio J, Goldstein SA. Type I collagen mutation alters the strength and fatigue behavior of Mov13 cortical tissue. J. Biomech. 1997;30:1141. 
[81] Vashishth D, Gibson GJ, Khoury JI, Schaffler MB, Kimura J, Fyhrie DP. Influence of nonenzymatic glycation on biomechanical properties of cortical bone. Bone 2001;28:195.

[82] Rauch F, Glorieux FH. Osteogenesis imperfecta. Lancet 2004;363:1377.

[83] Misof K, Landis WJ, Klaushofer K, Fratzl P. Collagen from the osteogenesis imperfecta mouse model (oim) shows reduced resistance against tensile stress. J. Clin. Invest. 1997;100:40.

[84] Gautieri A, Uzel S, Vesentini S, Redaelli A, Buehler MJ. Molecular and Mesoscale Mechanisms of Osteogenesis Imperfecta Disease in Collagen Fibrils. Biophys. J. 2009;97:857.

[85] Gautieri A, Vesentini S, Redaelli A, Buehler MJ. Single molecule effects of osteogenesis imperfecta mutations in tropocollagen protein domains. Protein Sci. 2009;18:161.

[86] Buehler MJ, Yung YC. Deformation and failure of protein materials in physiologically extreme conditions and disease. Nat. Mater. 2009;8:175. 


\section{APPENDIX}

\section{Estimation of radiation exposures}

Bone samples in this study were all irradiated from hard x-rays produced from a superbend synchrotron source and double multilayer monochromator combination on beamline 8.3.2 at the Advanced Light Source at the Lawrence Berkeley National Laboratory (LBNL). All of the controls selected for irradiation were selected to mimic a realistic tomography scan. All reported dose values in text follow the same procedural dose calculations.

To estimate the radiation dose absorbed by the bone sample, which is measured in grays ( $\left.1 \mathrm{~Gy} \equiv 1 \mathrm{~J} \mathrm{~kg}^{-1}\right)$, the radiation flux density, $\psi$, is computed from the value of the flux, $\Phi$, measured from an ion chamber:

$$
\psi=\frac{\Phi}{z},
$$

where $z$ is the area of the beam at the sample. The flux density is then converted into an energy density $E_{\rho}$, using:

$$
E_{\rho}=\psi \times 1.6 \times 10^{-19} \mathrm{~J} / \mathrm{eV} \times E,
$$

where $E$ is the energy of the beam in $\mathrm{eV}$.

The transmission, $T$, of $\mathrm{x}$-rays through a material, of thickness $l$, is often expressed as:

$$
T=\frac{I}{I_{o}}=e^{-\alpha \rho l}
$$

where $I$ and $I_{0}$ are the transmitted and incident $x$-ray intensities respectively, $\alpha$ is the mass attenuation coefficient $\left(\mathrm{cm}^{2} / \mathrm{gm}\right)$ and $\rho$ the density. This is generally referred to as the Beer-Lambert Law. The linear attenuation coefficient $\mu\left(\mathrm{cm}^{-1}\right)$ is also commonly used and is related by: $\mu=\alpha \rho$. The fraction of x-rays absorbed $(A)$ by the sample is given as $(1-T)$. The dose rate, $\dot{d}$, can then be obtained from:

$$
\dot{d}=\frac{A E_{\rho}}{M}
$$


where $M$ is the mass of the bone absorbing the radiation. Given a reasonably uniform distribution for the absorption of x-rays within the sample, the total irradiation dose received during each exposure is then found from the dose rate and the total exposure time, $t$ :

$$
\text { Total irradiated dose }=\dot{d} \times t=\frac{A E_{\rho}}{M} \times t
$$


Table 1: Dose rates from typical in situ small angle x-ray scattering experiments and in situ synchrotron tomography experiments.*

\begin{tabular}{|c|c|c|c|c|c|c|}
\hline $\begin{array}{l}\text { Type of in situ } \\
\text { experiment }\end{array}$ & Synchrotron location & $\begin{array}{c}\text { Radiation } \\
\text { energy } \\
(\mathrm{keV})\end{array}$ & $\begin{array}{c}\text { Flux } \\
\text { (photons/s) }\end{array}$ & $\begin{array}{c}\text { Flux } \\
\text { density } \\
\text { (photons/s } \\
/ \mathrm{mm}^{2} \text { ) }\end{array}$ & $\begin{array}{c}\text { Radiation } \\
\text { dose rate } \\
(\mathrm{kGy} / \mathrm{s})\end{array}$ & $\begin{array}{l}\text { Typical } \\
\text { radiation } \\
\text { dose } \\
(\mathrm{kGy})\end{array}$ \\
\hline $\begin{array}{l}\text { Small-angle } x- \\
\text { ray scattering } \\
(\mathrm{SAXS})[27,29]\end{array}$ & $\begin{array}{l}\text { Hamburger } \\
\text { Synchrotronstrahlungslab } \\
\text { (HASYLAB), Deutsches } \\
\text { Elektronen-Synchrotron } \\
\text { (DESY) }\end{array}$ & 8.27 & $1 \times 10^{9}$ & $1.67 \times 10^{8}$ & $2 \times 10^{-4}$ & $\begin{array}{c}\sim 0.04- \\
0.12\end{array}$ \\
\hline $\begin{array}{l}\text { Wide-angle } x- \\
\text { ray scattering } \\
(\text { WAXS) }[25,31]\end{array}$ & $\begin{array}{l}\text { Advanced Photon Source } \\
\text { (APS), Argonne National } \\
\text { Laboratory }\end{array}$ & 80.7 & $1 \times 10^{10}$ & $1 \times 10^{12}$ & 0.2 & $\sim 6-30$ \\
\hline SAXS, WAXS & $\begin{array}{l}\text { Advanced Light Source } \\
\text { (ALS), Lawrence Berkeley } \\
\text { National Laboratory }\end{array}$ & 10 & $1.76 \times 10^{12}$ & $2.2 \times 10^{11}$ & 0.5 & $\sim 20$ \\
\hline $\begin{array}{l}\text { Tomography } \\
(\mu \mathrm{XCT})\end{array}$ & $\begin{array}{l}\text { Advanced Light Source, } \\
\text { Lawrence Berkeley } \\
\text { National Laboratory }\end{array}$ & $20-80$ & $8.4 \times 10^{13}$ & $2.1 \times 10^{11}$ & 0.12 & $\sim 1.3 \times 10^{3}$ \\
\hline $\begin{array}{l}\text { Tomography } \\
{[32,33]}\end{array}$ & $\begin{array}{l}\text { Swiss Light Source SLS, } \\
\text { Paul Scherrer Institute }\end{array}$ & 20 & $3 \times 10^{14}$ & $1.36 \times 10^{12}$ & 0.77 & $\sim 6.0 \times 10^{3}$ \\
\hline
\end{tabular}

* Estimation procedures are described in the Appendix 
Table 2: Mechanical properties of human cortical bone for the varying $x$-ray irradiation doses**

\begin{tabular}{|c|c|c|c|c|c|c|c|}
\hline \multirow{2}{*}{$\begin{array}{l}\text { Irradiation } \\
\text { dose } \\
\text { (kGy) }\end{array}$} & \multirow{2}{*}{$\begin{array}{c}\text { Bending } \\
\text { stiffness } \\
(\mathrm{GPa})\end{array}$} & \multirow{2}{*}{$\begin{array}{l}\text { Ultimate } \\
\text { bending } \\
\text { strength } \\
\text { (MPa) }\end{array}$} & \multirow{2}{*}{$\begin{array}{l}\text { Ultimate } \\
\text { bending } \\
\text { strain } \\
(\%)\end{array}$} & \multirow{2}{*}{$\begin{array}{l}\text { Work-to- } \\
\text { fracture } \\
\left(\mathrm{kJ} / \mathrm{m}^{2}\right)\end{array}$} & \multirow{2}{*}{$\begin{array}{c}\text { Crack- } \\
\text { initiation } \\
\text { toughness, Ko } \\
(\mathrm{MPa} \sqrt{\mathrm{m}})\end{array}$} & \multicolumn{2}{|c|}{$\begin{array}{c}\text { Crack-growth } \\
\text { toughness }\end{array}$} \\
\hline & & & & & & $\begin{array}{c}\mathrm{d} K / \mathrm{d} \Delta a \\
(\mathrm{MPa} \sqrt{ } \mathrm{m} / \mathrm{m} \\
\mathrm{m})\end{array}$ & $\begin{array}{c}K_{\mathrm{Jc}} \\
(\mathrm{MPa} \sqrt{ } \\
\mathrm{m})\end{array}$ \\
\hline 0 & $\begin{array}{c}1.37 \\
(0.51)\end{array}$ & $\begin{array}{l}166.9 \\
(10.4)\end{array}$ & $1.6(0.2)$ & $\begin{array}{c}16.7 \\
(0.8)\end{array}$ & $1.77(0.19)$ & $31.8(3.0)$ & 13.3 \\
\hline 0.05 & $\begin{array}{c}0.81 \\
(0.42)\end{array}$ & $\begin{array}{c}172.8 \\
(8.5)\end{array}$ & $1.8(0.3)$ & $\begin{array}{l}19.3 \\
(0.7)\end{array}$ & $1.12(0.23)$ & 23.9 (3.3) & 10.5 \\
\hline 70 & $\begin{array}{c}1.43 \\
(0.24)\end{array}$ & $\begin{array}{c}126.5 \\
(1.8)\end{array}$ & $1.0(0.3)$ & $\begin{array}{c}5.58 \\
(0.91)\end{array}$ & $0.85(0.17)$ & $19.8(2.4)$ & 7.4 \\
\hline 210 & $\begin{array}{c}1.20 \\
(0.17)\end{array}$ & $\begin{array}{c}65.4 \\
(0.01)\end{array}$ & $0.6(0.1)$ & $\begin{array}{c}2.22 \\
(0.25)\end{array}$ & $0.73(0.07)$ & $5.45(0.53)$ & 2.7 \\
\hline 630 & $\begin{array}{c}1.53 \\
(0.44)\end{array}$ & $20.0(1.1)$ & $0.3(0.1)$ & $\begin{array}{c}0.22 \\
(0.05)\end{array}$ & - & - & - \\
\hline
\end{tabular}

** Standard deviations in parentheses. 
Table 3: UV-Raman spectroscopy data showing the relative intensity (height) of the amide I feature, as compared to the height of the $\mathrm{CH}_{2}$ wag peak ${ }^{* * *}$

\begin{tabular}{cc}
\hline \hline $\begin{array}{c}\text { Irradiation dose } \\
(\mathrm{kGy})\end{array}$ & $\begin{array}{c}\text { Amide I peak relative to the } \\
\mathrm{CH}_{2} \text { wag peak }\end{array}$ \\
\hline 0 & $0.81(0.01)$ \\
\hline 0.05 & $0.81(0.12)$ \\
\hline 70 & $1.05(0.11)$ \\
\hline 210 & $1.20(0.15)$ \\
\hline 630 & $1.39(0.15)$ \\
\hline
\end{tabular}

*** Standard deviations in parentheses. 


\section{Structure}

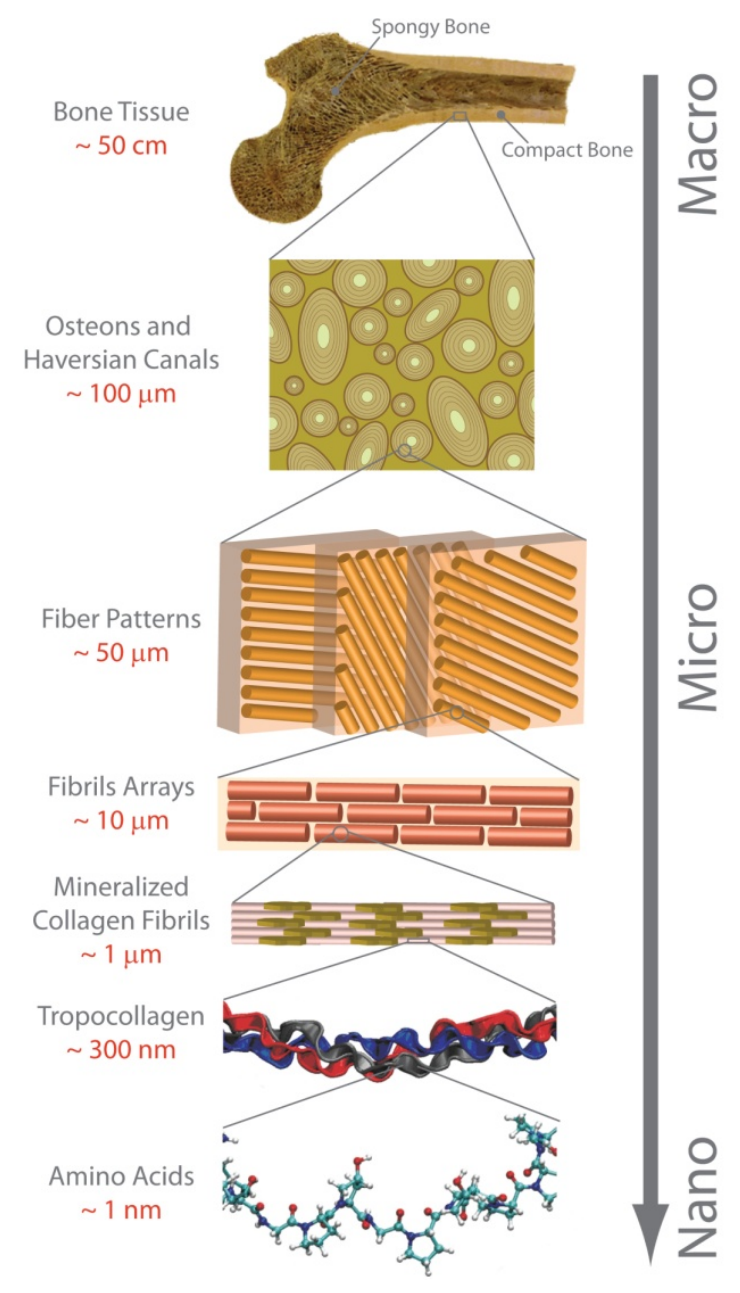

\section{Mechanism}
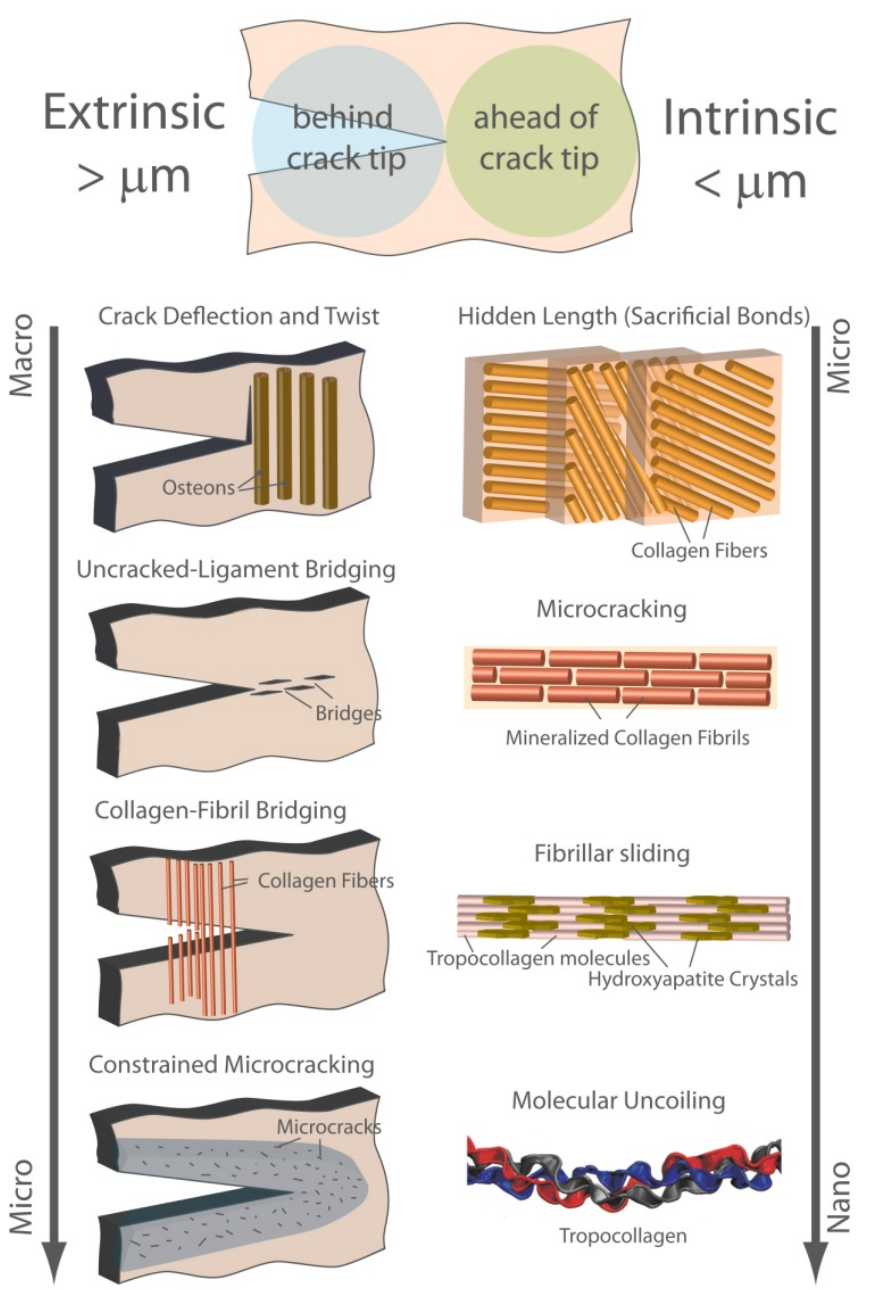

Figure 1: The structure of bone showing the seven levels of hierarchy with the prevailing toughening mechanisms. At the smallest level at the scale of the tropocollagen molecules and mineralized collagen fibrils, (intrinsic) toughening, i.e., plasticity, is achieved via mechanisms of molecular uncoiling and intermolecular sliding of molecules. At coarser levels at the scale of the fibril arrays, microcracking and fibrillar sliding act as plasticity mechanisms and contribute to the intrinsic toughness. At micrometer dimensions, the breaking of sacrificial bonds at the interfaces of fibril arrays contributes to increased energy dissipation, together with crack bridging by collagen fibrils. At the largest length-scales in the range of $10 \mathrm{~s}$ to $100 \mathrm{~s} \mu \mathrm{m}$, the primary sources of toughening are extrinsic and result from extensive crack deflection and crack bridging by uncracked ligaments, both mechanisms that are motivated by the occurrence of microcracking. (Adapted from Ref. [40]). 

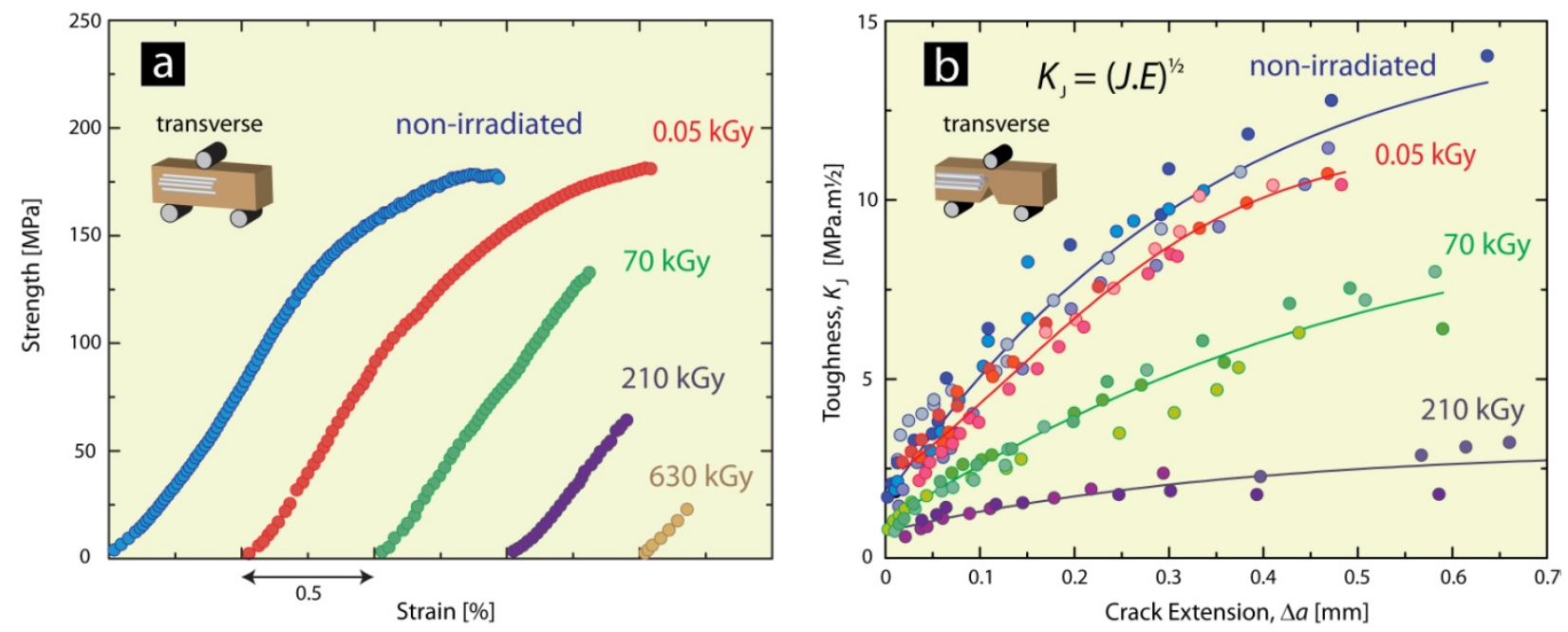

Figure 2: Mechanical properties of human cortical bone subjected to varying degrees of x-ray irradiation. (a) Stress-strain curves from three-point bending tests (offset for clarity) for hydrated human cortical bone in the transverse orientation at different irradiation levels. (b) Crack-resistance curves (R-curves) showing resistance to fracture in terms of the stress intensity, $K_{\mathrm{J}}$, as a function of crack extension, $\Delta a$, for human cortical bone in the transverse orientation. $K_{\mathrm{J}}$ fracture toughness values were back-calculated from the $J$ measurements using the $J-K$ equivalence for mode I fracture. The end of the curves indicates the critical toughness values, $K_{\mathrm{Jc}}$, at which complete failure occurred. 

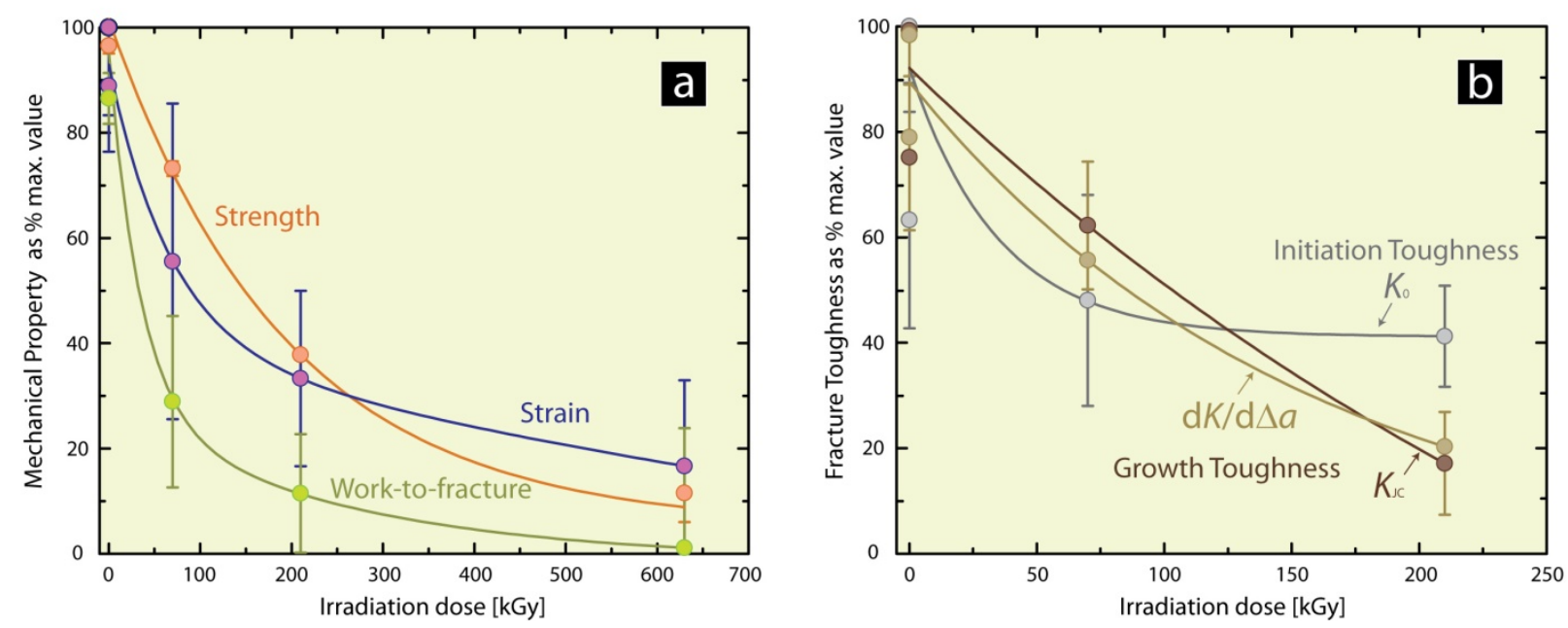

Figure 3: Changes in mechanical properties of hydrated human cortical bone with irradiation dose. (a) The effects of irradiation on the ultimate bending stress and strain, and work-tofracture of hydrated human cortical bone. (b) Corresponding effects of irradiation on the crackinitiation toughness, $K_{\mathrm{o}}$, and crack-growth toughness, $\mathrm{d} K / \mathrm{d} \Delta a$ and $K_{\mathrm{Jc}}$. The graphs show that there is a severe and progressive degradation in mechanical properties, specifically in the bending stress/strain and toughness properties, with increase in x-ray irradiation dose. Values plotted are normalized to the highest value for each group $(=100 \%)$. 
Non-irradiated bone
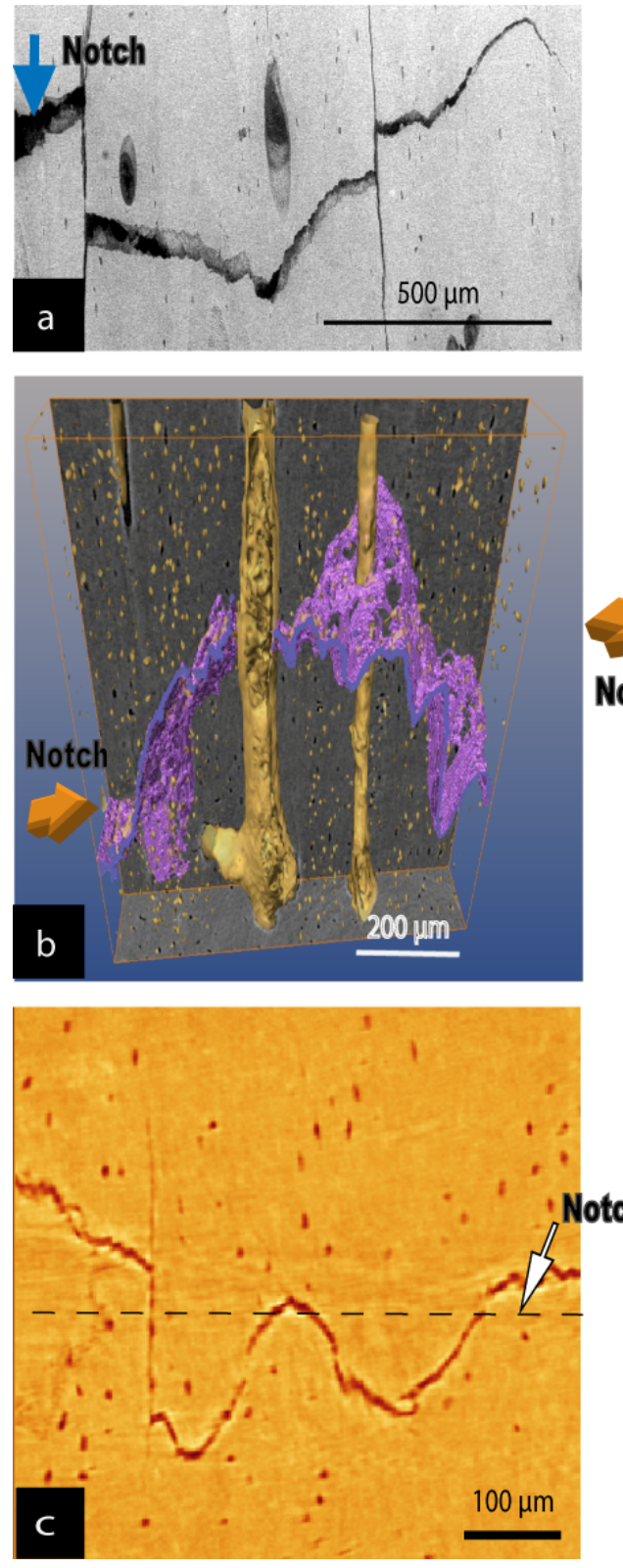

$210 \mathrm{kGy}$ irradiated bone
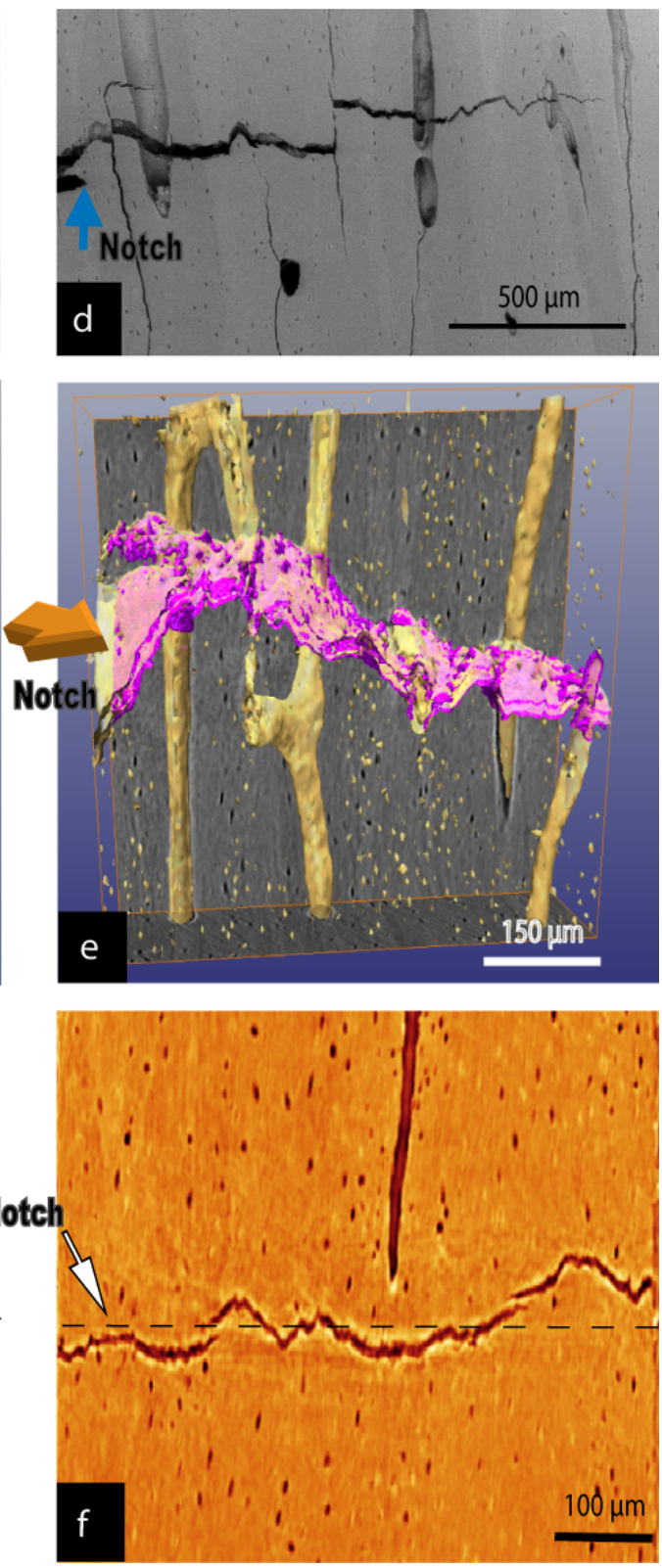

Figure 4: Scanning electron microscopy and computed $x$-ray tomography of crack paths in (a-c) non-irradiated and (d-f) 210 kGy irradiated hydrated human cortical bone (transverse orientation). Images of fracture in the non-irradiated and irradiated bone showing crack paths: (a) \& (d) SEM micrographs from side-view perpendicular to the crack plane, (b) \& (e) 3-D x-ray tomography images of these paths (notch shown by orange arrow; crack surface is purple/pink; Haversian canals are yellow), and (c) \& (f) 2-D tomographs of the paths from the back face of the sample. The crack deflects on encountering the osteons; such crack deflection and crack twisting is the prime extrinsic toughening mechanism in bone in the transverse orientation. Note, however, that the frequency of such deflections is increased whereas their severity is decreased with irradiation, resulting in less meandering crack paths in irradiated bone. 


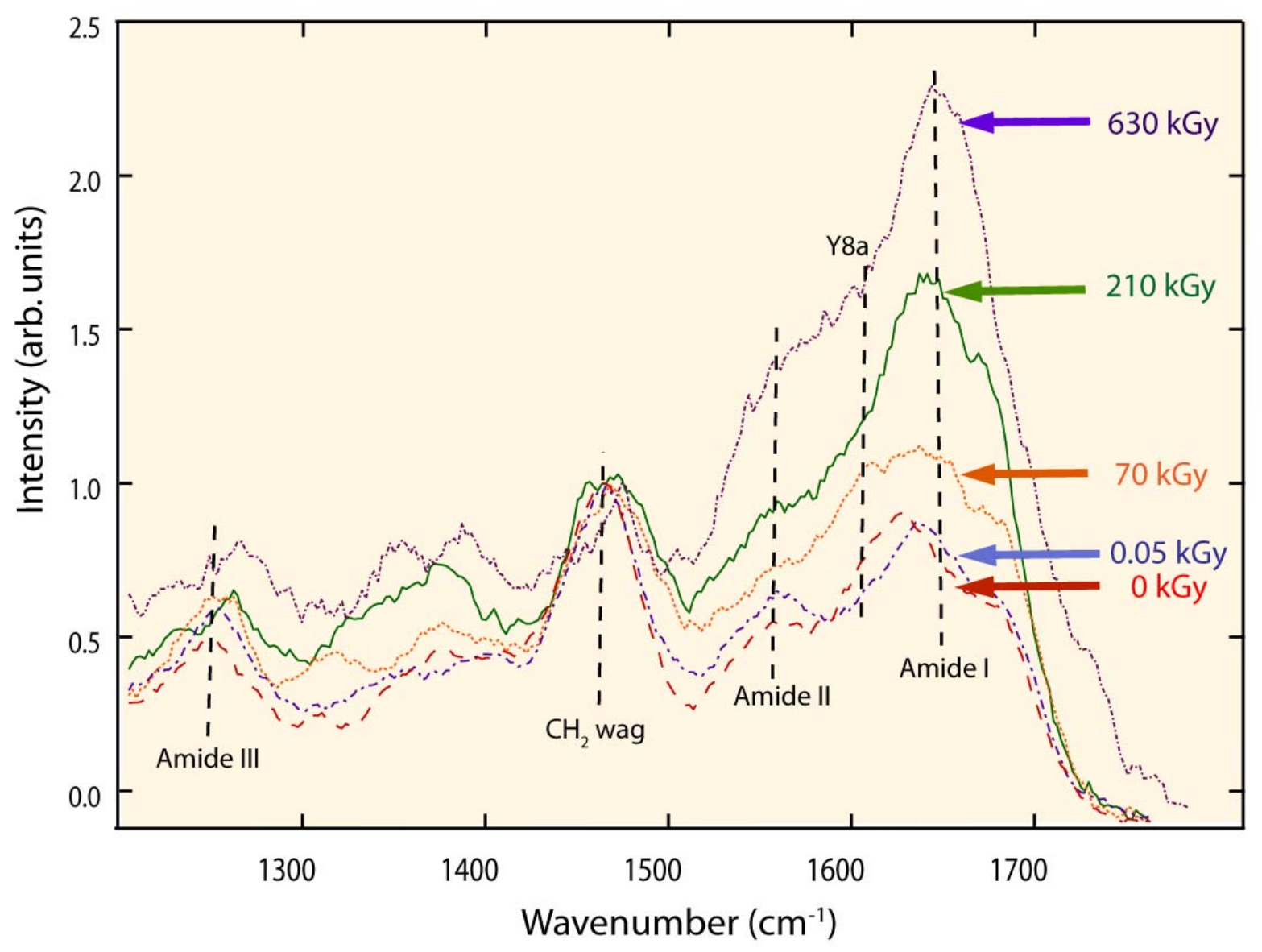

Figure 5: UV-Raman spectroscopy of irradiated hydrated human cortical bone. (a) UVRaman spectra for four different irradiation groups after doses of 0, 0.05, 70, and $210 \mathrm{kGy}$, showing specifically the large changes in the relative height of the amide I feature compared to the $\mathrm{CH}_{2}$ wag peak. The amide I (primarily from $\mathrm{C}==\mathrm{O}$ stretch) peak has previously been a good indicator for observing changes in the protein arrangement since the amide is known to play a role in cross-linking and bonding. The amide I peak height of the peak monotonically increases with irradiation, consistent with an increase in cross-linking in the collagen. Some of the other noticeable organic features for the bone matrix are the $\mathrm{CH}_{2}$ wag peak (1454-1461 $\mathrm{cm}^{-1}$ ), amide III (primarily from in-phase combination of NH in-plane bend and CN stretch, $1245-1260 \mathrm{~cm}^{-1}$ ), and amide II (primarily from out of phase combination of $\mathrm{NH}$ in-plane bend and $\mathrm{CN}$ stretch). 